\title{
Professores de história em uma experiência de formação inicial a distância: os significados e os limites da profissionalização
}

\author{
History teachers in an experience of learning at distance: \\ the meanings and limits of the professional development
}

Maria Cláudia Cardoso Ferreira*

\section{RESUMo}

$\mathrm{O}$ artigo analisa uma experiência de formação a distância (Pró-licenciatura) destinada a professores leigos que atuavam como professores de história no Nordeste brasileiro. Mediante análise de entrevistas, de questionários e das interações no fórum de debates online do curso objetivou-se compreender, da perspectiva dos saberes docentes, o processo de fazer-se professor de história. Com isso foi possível elucidar aspectos das políticas de qualificação profissional dos professores da educação básica em geral, e de história, em particular, bem como constatar que a educação a distância pode significar uma possibilidade real de formação superior, oportunizando mobilidade social e inclusão digital e rompendo barreiras de acesso às Tecnologias Digitais de Informação e Comunicação (TDICs), especialmente para professoras com exaustiva jornada de trabalho e muitos anos de profissão.

Palavras-chave: ensino a distância; licenciatura em história; formação de professores.

\section{Abstract}

The article analyzes the experience of distance training (Pró-licenciatura) addressed to lay teachers who acted as history teachers in the Brazilian Northeast. Through the analysis of interviews, questionnaires and interactions held on the online forum of the course we intended to understand, under the perspective of teacher's knowledge, the process of becoming a history teacher. It was then possible to elucidate some aspects involved in the politics of professional qualification of teachers, both from basic education in general and history teachers in particular. It was also possible to note that distance education can mean a real possibility of higher education, providing opportunities for social mobility and digital inclusion, breaking barriers of access to TDICs especially for teachers with exhaustive working day and many years of experience.

Keywords: Distance education; teacher training in history; teacher training.

\footnotetext{
**Departamento de Geografia e História, Universidade Federal do Piauí (UFPI).mariacardoso2@ gmail.com
} 
Há algumas décadas a combinação de diferentes variáveis vem influenciando a procura pela carreira do magistério como profissão. No Brasil e em outros países tem sido um desafio contratar e reter professores no exercício da profissão (ver Moon, 2008). Os ínfimos salários que obrigam o profissional a atuar com carga horária extensa, os problemas de violência direta e simbólica sofridos em algumas instituições, o baixo prestígio social decorrente das representações negativas sobre a profissão, além dos problemas intrínsecos às políticas de formação de professores contribuem para a pouca procura pelos cursos de licenciatura e pedagogia ou, quando ocorre a matrícula, para uma expressiva evasão.

Esses problemas acabam repercutindo na sala de aula, espaço no qual os professores deveriam estar. Quando eles não estão, é comum que os gestores brasileiros resolvam a situação de duas maneiras: suspensão das aulas até que se empregue outro professor ou contratação de mão de obra sem qualificação suficiente ou adequada. A primeira medida não agrada à população, expõe os gestores e, de imediato, pode afastar os eleitores. Já o emprego de professores leigos tem servido, ao longo de décadas, como paliativo em muitas situações, seja na escola pública, seja na particular.

Dados de 2003, analisados pelo Instituto Nacional de Estudos e Pesquisas Educacionais Anísio Teixeira (Inep) em uma publicação de 2007, informam que, nas séries finais do ensino fundamental, 26,21\% dos cargos eram ocupados por professores leigos. Esse conjunto era constituído por professores que fizeram ou o chamado curso normal ou apenas o ensino médio, ou ainda por aqueles que tinham uma faculdade, mas não eram licenciados. Cerca de 180 mil profissionais atuavam nas séries do ensino fundamental, do $1^{\circ}$ ao $9^{\circ}$ ano, sem a formação exigida. Já no ensino médio havia 54 mil docentes sem a qualificação pertinente, ou seja, 14,74\% dos professores atuantes no país não eram licenciados. Essa percentagem aumenta se considerarmos apenas os dados do Nordeste, onde 44,07\% dos professores não tinham licenciatura em 2003 (Brasil/CNE/CEB, 2007).

Vale destacar que esses números não especificam os cursos, o que sugere haver distorções - por exemplo, profissionais licenciados formados em história que atuam também como professores de filosofia e sociologia, e pedagogos lecionando geografia, história, matemática etc. Como essa prática é muito 
comum, constata-se que faltariam muito mais professores caso fosse proibido lecionar fora da área de formação. A maioria das estatísticas geralmente só conta quantos alunos estão sem professor ou com professores não licenciados, deixando de lado as distorções, ou seja, quantos alunos estão com um professor na sala de aula que não tem a formação específica para ministrar determinada disciplina. Segundo o mesmo relatório faltavam hipoteticamente 19.937 professores de história na primeira década do milênio, já que a demanda era de 94.603 profissionais, mas apenas 74.666 concluíram a licenciatura entre 1990 e 2001 (Brasil/CNE/CEB, 2007).

A Lei de Diretrizes e Bases da Educação Nacional aprovada em 1996 reflete as orientações da Declaração Mundial sobre Educação Para Todos, aprovada em Jomtien, Tailândia, no ano de 1990, e ratificada pelo Estado brasileiro, que assumiu, entre outros, o compromisso da universalização do acesso ao ensino fundamental. Com o Marco de Ação de Dakar, assinado em 2000, durante o Fórum Mundial de Educação, outras metas foram estabelecidas. A demanda por mais professores e por uma educação de qualidade reflete o processo de democratização que vivemos nas últimas décadas. ${ }^{1}$

Tanto nas proposições de 1990 quanto nas de 2000, o trabalho do professor é colocado em posição crucial para o alcance da qualidade do ensino público. ${ }^{2} \mathrm{O}$ documento de Dakar estabeleceu que os países se comprometessem com metas e estratégias, sendo uma delas "elevar o status, o moral e o profissionalismo dos professores", colocando-os no lugar de atores essenciais, defensores e catalizadores da mudança, devendo por isso ser respeitados e adequadamente remunerados. $\mathrm{O}$ documento propugna ainda oferecer formação de professores permanente, aberta e a distância, promover a participação dos docentes nas esferas locais e nacionais nas decisões que envolvem a educação, criar ações bem definidas e imaginativas para atrair e reter os bons professores conscientes do seu papel em uma "economia emergente, baseada no conhecimento e conduzida pela tecnologia" e capazes de usar as novas Tecnologias de Informação e Comunicação para atingir os objetivos da Educação para Todos (Unesco/Dakar, 2001). O texto de Dakar tem um anexo composto de metas a serem cumpridas pelos países americanos, com vistas a melhorar a qualidade da educação básica, as quais incluem os docentes. De acordo com o documento, é preciso 
recuperar o valor social e profissional dos docentes como atores insubstituíveis dos processos educativos de qualidade, mediante estabelecimento de políticas ajustadas de qualificação, melhora das condições de trabalho e remuneração e incentivos para a sua constante superação. (Unesco/Dakar, 2001, p.33)

Este artigo apresenta parte das análises e apontamentos apresentados em minha tese de doutorado (Ferreira, 2013) realizada no Programa de Pós-Graduação em História, Política e Bens Culturais do Centro de Pesquisa e Documentação de História Contemporânea do Brasil da Fundação Getulio Vargas (CPDOC/FGV). A pesquisa investigou um curso de licenciatura em história a distância, coordenado pela Pontifícia Universidade Católica (PUC) do Rio de Janeiro e pela Universidade do Estado do Rio de Janeiro (Uerj), entre 2006 e 2011. O curso se destinava a professores leigos, funcionários públicos, que lecionavam história havia pelo menos um ano, nos estados da Bahia, Ceará, Maranhão e Sergipe. O curso foi financiado pelo Ministério da Educação (MEC) através do Programa Pró-Licenciatura Fase II, no bojo das políticas públicas de qualificação docente.

A questão principal da pesquisa foi investigar os saberes e práticas docentes mobilizados no âmbito da formação de professores de história com a obrigatoriedade do ensino de história e cultura afro-brasileira após a Lei 10.639/2003, que tornou obrigatório o ensino de história e cultura afro-brasileira nas escolas do país. Combinando a noção de saberes docentes, conforme as proposições de Tardif (2010) e Monteiro (2007), com a de trajetórias, ancorada em Bourdieu (1996), busquei analisar o percurso formativo dos profissionais no decorrer dos anos de existência do curso (Tardif, 2010; Monteiro, 2007; Bourdieu, 1996). Nessa lógica, trabalhei com o que Paim (2007) denomina processo de fazer-se professor (Paim, 2007). Essa argumentação assinala que devemos considerar, na formação, as experiências do antes e do durante, a memória, a história aberta, o fazer-se sujeito de um processo de formação que ocorre ao longo da vida.

Vali-me de fontes de diferentes procedências para realizar a pesquisa. Trabalhei com os documentos institucionais do curso e das políticas públicas em análise e com os registros escritos (postagens) de alunos e professores no ambiente de aprendizagem virtual. Além disso, analisei dados gerados por entrevistas presenciais e questionários enviados por e-mail realizados no ano de 2012 . 
Neste trabalho primeiramente apresento a experiência do consórcio PUC/ Uerj, com destaque para a sua inserção no âmbito das políticas públicas de formação docente. No segundo momento, busquei caracterizar e contextualizar o processo de desenvolvimento profissional dessa experiência, com foco na peculiaridade do ensino a distância, assinalando seus limites e possibilidades, através das vozes dos próprios profissionais envolvidos com a formação.

\section{Pró-Licenciatura II: o Percurso de um} PROGRAMA DE FORMAÇÃO INICIAL EM SERVIÇO

O consentimento para o funcionamento da formação superior (inicial e continuada) na modalidade de educação a distância consta no texto da Lei de Diretrizes e Bases da Educação Nacional de $1996 .{ }^{3}$ Com o Plano Nacional de Educação, em 2001, essa modalidade de ensino passou a ser proposta pelos gestores públicos como uma saída para resolver o histórico deficit de professores no país. ${ }^{4}$ Caberia aos gestores da Secretaria de Educação a Distância (SEED), ${ }^{5}$ criada em maio de 1996, desenhar as ações em conjunto com a Secretaria de Educação Básica (SEB) e com a colaboração das secretarias de Educação Especial (SEESP) e de Educação Superior (SESu). As instituições de ensino superior (IES) públicas foram conclamadas a entrar no empreendimento, assim como, num primeiro momento, as organizações de ensino superior, beneficentes e confessionais - caso da Pontifícia Universidade Católica do Rio de Janeiro (PUC-Rio). Quatro programas de formação específicos para professores foram gestados no MEC: a Rede Nacional de Formação Continuada de Professores da Educação Básica, o Pró-Letramento, o Pró-Licenciatura e a Universidade Aberta do Brasil (UAB). ${ }^{6}$

O Programa de Formação Inicial para Professores dos Ensinos Fundamental e Médio - Pró-Licenciatura constituiu-se num programa do Ministério da Educação cujo objetivo era ofertar cursos de licenciatura na modalidade a distância para municípios com maior carência de professores ou com um grande número de professores leigos.

O programa teve duas fases. O Pró-Licenciatura I foi instituído pela chamada pública SEED/MEC no 01/2004, com início no mesmo ano e atenção voltada aos egressos do ensino médio, sensibilizados para exercer a profissão de professor, com atenção às áreas de pedagogia, matemática, física, química 
e biologia. O Pró-licenciatura II foi instituído pela Resolução FNDE n 34/2005 e teve início em 2006. Ele esteve direcionado aos professores leigos, incluindo nessa denominação tanto aqueles que não tinham qualquer formação superior como os que tinham uma licenciatura, mas lecionavam fora da sua formação. Em números absolutos, o programa disponibilizou 29.585 vagas, com 18 cursos para a fase I e 28 para a fase II. O Pró-Licenciatura não lançou mais editais e sua estrutura foi incorporada, paulatinamente, ao sistema UAB, à medida que este se institucionalizava no ano de 2006.

\section{A LICENCIATURA EM HISTÓRIA A DISTÂNCIA DO CONSÓRCIO PUC-RIO/UERJ}

Em novembro de 2006, o Departamento de História da PUC-Rio iniciava as aulas de sua primeira experiência de ensino de graduação totalmente a distância, com a licenciatura em história. O consórcio PUC-Rio/Uerj foi pioneiro também para o MEC, pois, para todas as outras propostas aprovadas, o vestibular estava marcado para o início de 2007. Por isso, o curso acabou servindo como um experimento de gestão, bem como dos modos de ensinar e aprender frente a uma modalidade de ensino ainda nova tanto para docentes e coordenadores do consórcio quanto para os fomentadores da política.

Após um processo seletivo que constou de um exame de redação e conhecimentos gerais, iniciaram-se as turmas dos estados da Bahia, Maranhão e Sergipe. Já as atividades no estado do Ceará se iniciaram um pouco depois, em março de 2007. No total foram 1.003 professores-alunos matriculados. Os exames de acesso foram realizados nos estados dos pretendentes sob a responsabilidade de instituições locais de gestão da educação. No estado da Bahia, o Instituto Anísio Teixeira (IAT) cuidou do vestibular, assim como da análise dos documentos necessários à matrícula dos alunos, e proporcionou toda a estrutura física do curso ao longo dos anos de formação. No Ceará, as inscrições foram administradas pela União Nacional dos Dirigentes Municipais de Educação (Undime), ${ }^{7}$ que contatou as secretarias municipais de Educação e fez as inscrições dos alunos. No Maranhão e em Sergipe, as secretarias estaduais de Educação responderam pelas inscrições e estruturas locais. Todos os documentos dos candidatos foram remetidos ao Departamento de História da PUC-Rio, que viabilizou a matrícula na instituição. 
O curso de licenciatura em história a distância esteve sob a coordenação geral do próprio diretor do Departamento de História, na época, o professor Luís Reznik. O suporte à direção vinha da coordenação acadêmica, da coordenação de tutores, que respondia por sessenta professores tutores a distância, e da secretaria geral do curso, sob a responsabilidade de um funcionário do Departamento de História e de uma bolsista de pós-graduação.

Para o curso acontecer, além das coordenações citadas, funcionava outra estrutura mais operacional. Ela começou com os professores autores, responsáveis por escrever os textos das 53 disciplinas. A maioria dos professores do grupo se constituiu de professores da PUC-Rio (28) e da Uerj (14), com alguns deles participando da elaboração de duas disciplinas. Do total de 49 professores, oito tinham mestrado na época, quatro eram doutorandos, e todo o restante se constituía de doutores.

$\mathrm{Na}$ sequência estavam os professores formadores, cuja responsabilidade era auxiliar os professores tutores presenciais e a distância na compreensão das aulas-texto, trabalhadas no ambiente virtual de ensino-aprendizagem denominado AulaNet, bem como mediar o contato com a coordenação geral. Por fim, no contato direto com os professores cursistas estavam os tutores presenciais e a distância. Havia um tutor para cada polo, somando 18 professores tutores presenciais. Os tutores a distância formavam uma equipe composta de aproximadamente sessenta professores. Os professores tutores a distância trabalharam, ao longo dos anos, com diversas disciplinas e em diferentes turmas e estados.

Cabia ao professor tutor presencial dar toda assistência ao aluno no polo, orientando-o nas tarefas, auxiliando-o no uso da internet, na consulta ao acervo da biblioteca etc., além de monitorar suas tarefas a fim de qualificar a aprendizagem. Já o professor tutor a distância mediava a aprendizagem da disciplina no decorrer do semestre, com a responsabilidade de interceder na relação aluno-texto, cobrar e corrigir as tarefas virtuais e criticar a participação, incentivando intervenções com mais consistência teórica e qualidade acadêmica.

A PUC-Rio fez a matrícula de 1.003 alunos. Destes, 656 estavam diplomados em fevereiro de 2012 e outros 109 aguardavam diploma porque havia algum tipo de pendência para sua emissão. A maioria do grupo terminou a licenciatura no final de 2010. A cerimônia de formatura aconteceu na cidade do Rio de Janeiro e contou com a presença de mais de trezentos formandos. 
No estado de Sergipe foram 68 formados; no Maranhão, 174; no Ceará, 228, e, na Bahia, o número chegou a 295 concluintes, resultando, portanto, na soma de 765 professores que deixaram de ser leigos no ensino de história.

Desse grupo que chegou ao final, aproximadamente $86 \%$ eram mulheres na faixa etária entre 40 e 50 anos no ano de conclusão do curso. Quanto ao grau de escolaridade tratava-se da primeira graduação de uma maioria de mulheres que tinha habilitação para lecionar somente nas séries iniciais da educação básica (educação infantil e fundamental I), pois se formaram no curso de magistério. Considerando a idade média dessas professoras, é possível inferir que elas fizeram o curso do magistério nas décadas de 1970 ou 1980, portanto, no contexto das reformas educacionais que buscaram acelerar a profissionalização dos professores como meio de cobrir a demanda resultante do aumento das matrículas. ${ }^{8}$ Entre os graduados, a maioria era formada em pedagogia, mas havia professores formados em biologia e filosofia, por exemplo, lecionando história.

\section{O EMPREENDIMENTO NOS ESTADOS}

As etapas presenciais do curso ocorriam nos Polos Municipais de Apoio Presencial, que eram a base do curso de licenciatura nos estados. Os polos estavam equipados com biblioteca, laboratórios de informática e salas de reunião, e alguns, com auditório. Nos polos aconteceram as aulas inaugurais, as capacitações para o uso da internet e da metodologia do ambiente de aprendizagem adotado pelo curso. $\mathrm{O}$ aluno podia ir ao polo caso precisasse usar a internet, realizar reuniões de grupo, estudos dirigidos, com ou sem acompanhamento do tutor, e usar a biblioteca. Nesses espaços também ocorreram as provas semestrais e as apresentações das monografias de final de curso. Os Polos Municipais de Apoio Presencial listados na Tabela 1 tiveram sua estrutura logística mantida pelo município em que se localizavam, e os recursos humanos e materiais foram gerenciados pelas IES. Atualmente todos os polos do programa Pró-Licenciatura foram incorporados ao sistema UAB. 
Tabela 1 - Polos Municipais de Apoio Presencial - número de turmas

\begin{tabular}{c|c|c|c}
\hline Sergipe & Ceará & Bahia & Maranhão \\
\hline Aracaju & Crato (2) & Guanambi (4) & São Luís (4) \\
(3 turmas) & Itapipoca (2) & Salvador (3) & Barra do Corda (2) \\
& Tianguá (2) & Juazeiro (1) & Bacabal (2) \\
& Jaguaribe (2) & Teixeira de Freitas (1) & Imperatriz (2) \\
& Aracati (2) & Feira de Santana (2) & \\
& Fortaleza (1) & Barreiras (1) & \\
& & Jequié (2) & \\
& & & \\
\hline
\end{tabular}

Fonte: Dados disponibilizados pela coordenação do curso de licenciatura em história a distância.

\section{O AMBIENTE VIRTUAL DE ENSINO E APRENDIZAGEM DO CURSO}

Como se tratava de um curso a distância, todo o conteúdo do curso de licenciatura em história foi adaptado para o já mencionado ambiente virtual de ensino-aprendizagem AulaNet por um conjunto de profissionais que constitui a equipe de design didático da Coordenação Central de Educação a Distância (CCEAD) da PUC-Rio. Coube à equipe a "criação da interface, roteirização e implementação do conteúdo no ambiente Web” (Roque; Castro, 2009, p.3).

O AulaNet foi configurado para o curso com os seguintes recursos: o plano de aula, onde estavam disponíveis os conteúdos; o contato com docente, que permitia a interação direta tutor-cursista; a lista de discussão, que viabilizava o envio de mensagens para toda a turma, incluindo o tutor; o fórum de debates, ambiente virtual separado por disciplina, que permitia as discussões sobre os conteúdos trabalhados nas aulas; a documentação, ambiente em que eram alocados textos extras e alguma legislação, ou ainda documentos históricos dos quais porventura o cursista deveria tomar conhecimento para apreender com mais propriedade o tema estudado, e a bibliografia e webliografia, que indicava livros, textos e sites para pesquisa (Campos; Roque; Fioroti, 2008). 
AS PERSPECTIVAS E OS SIGNIFICADOS DA

PROFISSIONALIZAÇÃO EM HISTÓRIA

Durante minha pesquisa, direcionei, aos diferentes sujeitos envolvidos com a formação, entre outras questões, algumas que buscavam elucidar os valores e as práticas educativas que se dão no ambiente de aprendizado do ensino a distância, bem como perceber as representações que essa modalidade de ensino tinha no cenário da profissionalização em história. Outro objetivo da pesquisa foi trazer à tona os questionamentos que porventura inquietaram meus interlocutores e, além disso, compreender o que significou a formação superior, em particular, e a formação em história para os professores cursistas.

Seis cursistas responderam ao chamado da pesquisa, sendo todas mulheres. Dos professores tutores a distância e presenciais obtive, entre questionários por e-mail e entrevistas, nove retornos. Também entrevistei o secretário do curso, Cláudio Santiago, e o professor Leonardo Affonso Miranda Pereira, autor, com a professora Ynaê Lopes dos Santos, da disciplina História da África, objeto principal do meu estudo na tese. ${ }^{9}$

Todas as seis professoras cursistas afirmaram que o curso trouxe benefícios econômicos, profissionais e pessoais, apesar de todas usarem os vocábulos "dificuldade", "difícil” e "sacrifício" para qualificar os anos de realização do curso. Uma respondente relatou ter priorizado sempre a formação em história e deu como exemplo a ocasião de internação da filha de 7 anos, quando, mesmo estando ali para acompanhá-la, não deixou de levar os módulos do curso para estudar no hospital (Questionário por e-mail, cursista, polo de Salvador, Bahia, 20 abr. 2012). Outras duas cursistas abordaram a dificuldade de conciliar o estudo, o trabalho e a vida de dona de casa. Outra relatou ter tido inúmeros conflitos no casamento, culminando em separação.

Das seis professoras, quatro eram formadas em pedagogia, uma em filosofia, e uma tinha a habilitação do magistério, nível ensino médio. No grupo das pedagogas, duas tinham pós-graduação. Conquistar o reconhecimento profissional e salário compatível com o trabalho desempenhado aparece como o principal objetivo da formação para as professoras cursistas investigadas. Especialmente para quem estava em vias de se aposentar, a oportunidade do curso foi muito bem-vinda, pois garantia um aumento da renda. A busca por 
uma especialização também apareceu como um dos motivos, já que, do grupo que tinha curso superior completo, a maioria era graduada em pedagogia, o que, na realidade de trabalho vivida por essas pessoas, significava muitas vezes lecionar várias disciplinas diferentes, ou seja, ser um professor polivalente, $\mathrm{o}$ que tornava o trabalho ainda mais extenuante por ser necessário elaborar diferentes planos de aula e lidar com conteúdos diversos.

Segundo a tutora presencial do polo de Teixeira de Freitas (BA), as professoras almejavam "ter segurança dentro da instituição e saber que teriam sua carga horária completa de história”. Para a professora Andréa Queiroz, tutora a distância do polo de Aracaju, a licenciatura em história significava que, além da melhoria salarial, os professores "com o diploma poderiam se dedicar apenas a esta disciplina ... muitos lecionavam outras disciplinas além de história (alguns davam aula de matemática e ciências)" (Questionário, tutora a distância, polo de Aracaju, Sergipe, 2 jul. 2013).

O depoimento desta cursista revela um percurso que, podemos supor, não é incomum para muitos dos professores:

Comecei a lecionar no ano de 1987 para turmas de $1^{\text {a }}$ à $4^{\text {a }}$ série do ensino fundamental e, com o passar do tempo, atuei nas turmas seguintes e até no ensino médio regular e magistério. No percurso docente ministrei várias disciplinas, como língua portuguesa, matemática, educação moral e cívica, educação para o lar, ciências, didática, redação, metodologia da língua portuguesa, educação religiosa, geografia e, mais recentemente, história. (Questionário por e-mail, cursista, polo de Guanambi, Bahia, 29 mar. 2012)

As condições para o exercício do magistério no país revelam-se ainda mais complexas ao analisarmos o relato seguinte. São trajetórias de professoras que começaram a lecionar sem ao menos ter um curso de formação de professores:

Iniciei minha carreira na rede municipal de ensino. Como na época só havia estudado até a $3^{a}$ série, trabalhava com alfabetização. Hoje tenho a oportunidade de ver alguns desses antigos alunos formados em direito, administração e outros. Somente no ano de 1982, quando ingressei na rede estadual, é que comecei a trabalhar a disciplina história no ensino fundamental menor ( $1^{\mathrm{a}}$ a $4^{\mathrm{a}}$ série). A partir do ano 2000 fui designada para trabalhar a disciplina história de $5^{\mathrm{a}}$ a $8^{\mathrm{a}}$ 
série na escola em que atuo. (Questionário por e-mail, cursista, polo de Bacabal, Maranhão, 17 mar. 2012)

Essa professora já era licenciada em filosofia quando começou o curso de licenciatura em história. Ela não informou quando fez a sua primeira licenciatura, mas é bastante reveladora a constatação de que essa profissional lecionou história por tanto tempo nas redes municipal e estadual sem a formação pertinente.

As cursistas disseram que, com o curso, passaram a lecionar de outra maneira, a estranhar os textos que antes liam com naturalidade e a considerar outras falas e outros lugares nas narrativas que faziam. Se o aumento salarial era a motivação inicial, com o desenvolvimento da formação, a oportunidade de potencializar o trabalho na sala de aula parece surgir como uma conquista importante. Segundo uma professora de Salvador, por exemplo, "uma das coisas que aprendi na licenciatura foi desenvolver no aluno seu senso crítico e sua importância como agente histórico" (Questionário por e-mail, cursista, polo de Salvador, Bahia, 20 abr. 2012). No mesmo sentido, a docente da cidade de Guanambi destacou as especificidades dos saberes concernentes ao ensino de história em seu questionário:

repensando no "meu antes" e o "depois", notei que deixei a desejar no meu ensino de história por conta da falta de habilidades específicas. Certamente, sinto-me mais segura hoje e capaz de discutir as questões sobre história, principalmente saber criticar e compreender os contextos em que foram produzidos os livros didáticos, entre outros assuntos. (Questionário por e-mail, cursista, polo de Guanambi, Bahia, 29 mar. 2012)

No aspecto profissional, esses saberes apreendidos deram significado ao trabalho docente. A mesma professora relata ter, ao término do curso,

maior embasamento teórico e prático (na hora da produção monográfica) e condições de ensinar história com maior qualidade. Possuir capacidade de entender a construção da história ao longo dos tempos e dos homens no seu contexto de convivências. (ibidem)

$\mathrm{Na}$ avaliação dos professores tutores, guardadas as singularidades dessa modalidade de formação e considerando-a na sua totalidade, os alunos os 
surpreenderam e superaram as expectativas iniciais. Segundo o professor tutor presencial Francisco Gleison da Costa Monteiro,

muitos professores começaram a notar a educação, a metodologia e, principalmente, o ensino de história de forma diferente do habitual. Digo, da estrutura positivista que estudamos nos livros didáticos de história e da forma como os alunos a tomam - disciplina como chata e cansativa. Conseguiram romper com os paradigmas tradicionais da história. (Questionário por e-mail, polo de Tianguá, Ceará, 2 out. 2012)

Análises em consonância com essa tiveram duas professoras tutoras a distância, que trabalharam com diferentes disciplinas ao longo do curso. Em seus depoimentos essas professoras não se furtaram de apontar as limitações presentes na modalidade de ensino a distância quando comparado ao presencial, no entanto, conseguiram identificar ganhos na formação, ou seja, caracterizar o processo de formação dos professores-leigos, o processo de aprender a ensinar história. Vejamos:

Eles sentiram muita diferença do que é de fato história que a gente passa. Que não é essa história do livro decorada. Aprenderam [a] dar a visão do conquistador, do conquistado, então ampliaram a forma de trabalhar. Melhorou. Começaram a trabalhar com documentos, que dá para levar para a sala de aula, imagens. (Entrevista, tutora a distância, polo de Aracati, Ceará, 18 set. 2012)

Eu acho que eles aprenderam a lidar melhor com a informática e com essa cobrança de leituras de graduação, mesmo porque tinha uma quantidade de leituras. Então eu acho que, na maioria dos casos, o que me fica assim, apesar de o curso já estar distante... Eu acho que foi um ganho para eles. Eu acho que, longe do que deveria ser, mas eu acho que foi válido. Eles evoluíram em aspectos básicos, o contato com a informática, com a rede, com a leitura de textos acadêmicos, que eles não tinham. Com a escrita em ter [que] realizar resenha, trabalhos de textos acadêmicos. Eu acho que eles evoluíram. Muito diferente do que se exige de uma graduação presencial nas grandes universidades brasileiras. (Entrevista, tutora a distância, polo de Aracaju, Sergipe, 13 set. 2012)

A tutora a distância do Polo de Aracati destacou a confiança que esses profissionais foram adquirindo com o decorrer dos anos, especialmente para 
pensar a própria aula e deixar de ser apenas seguidores de um manual didático. Para a tutora de Aracaju foi significativa a aprendizagem em Tecnologias Digitais de Informação e Comunicação (TDICs) e a necessidade da escrita que a formação impunha. Nas disciplinas "tutoria", que foram cinco ao longo do curso, os professores cursistas foram apresentados às regras da escrita e da pesquisa acadêmica. Essa tutora a distância participou de diversas disciplinas ao longo dos 4 anos de formação em história e pôde acompanhar o crescimento acadêmico do grupo.

Cláudia Miranda (2009) alerta para o lugar de subalternidade conferido às mulheres na sociedade, traduzido, inclusive, nas relações que se dão na escola pública entre professoras não leitoras oriundas de setores médios e empobrecidos e seus alunos também subalternizados. Nessa experiência de profissionalização em história devemos considerar, além dessa peculiaridade, as dificuldades que professoras e professores têm de escrever, ou seja, de elaborar textos autorais para serem usados nas aulas.

As representações em torno da PUC-Rio e da Uerj parecem ter aumentado a credibilidade do projeto e potencializado o senso de responsabilidade dos cursistas. Segundo a tutora a distância do polo de Aracaju, o fato de o curso estar vinculado às duas universidades "era (motivo) de muito orgulho para eles. Eu cheguei a dar um curso presencial em Salvador e, assim, o orgulho pra eles... Estive na formatura, o orgulho para eles de ter um diploma da PUC e da Uerj era o máximo" (Entrevista, tutora a distância, polo de Aracaju, Sergipe, 13 set. 2012). Em seus relatos, professores tutores presenciais e a distância argumentam também que a eficácia se deveu à postura da coordenação geral do curso em manter o mesmo nível de cobrança do início ao final da formação. Os cursistas começaram então a se disciplinar. No final "todos sonhavam em concluir o curso e colar grau na PUC, conhecer o Rio de Janeiro" (Questionário por e-mail, Francisco Gleison da Costa Monteiro, tutor presencial, polo de Tianguá, Ceará, 2 out. 2012). Do mesmo modo, para o secretário do curso, “a PUC era como se estivessem na Nasa. Nem a faculdade pública do estado era vista como mais importante do que a PUC. Essa visão também se deve às novelas, pois muitas locações são feitas na PUC, como o filme Tropa de Elite em que as cenas do professor universitário foram feitas na PUC" (Entrevista, Cláudio Santiago, 8 mar. 2012). 
Outro fator a conferir crédito ao empreendimento foi o vínculo direto do professor Ilmar Rohloff de Mattos com o curso. Autor de vários livros e com consolidada trajetória profissional nos diferentes níveis de ensino, o professor Ilmar Mattos esteve na coordenação acadêmica, foi um dos docentes-autores e ministrou a conferência na aula inaugural do estado da Bahia. Ele deu chancela ao projeto, pois, para os docentes, representa competência e credibilidade no meio dos profissionais de história.

Contudo, essa não parecia ser a regra em outros cursos de formação a distância em vigor no período. Apesar de a SEED estabelecer que só autorizaria projetos que envolvessem o quadro acadêmico efetivo da instituição, o monitoramento do biênio 2006-2008 realizado pelo Tribunal de Contas da União (TCU) constatou, pelo menos em relação ao sistema UAB, a oposição entre o ensino a distância e o ensino presencial. $\mathrm{Na}$ época foi destacado que faltava regulamentar as atribuições e o funcionamento do sistema, pois, no geral, o curso a distância ficava como uma ação periférica na instituição proponente (cf. Brasil/TCU, 2009).

A razão de o trabalho ser pago via bolsa e não poder computar como carga horária na instituição, nem como atividade acadêmica, apareceu, no relatório do TCU, como um problema que influenciava a participação e a aceitação do ensino a distância nas instituições. A contratação de professores tutores extraquadros também contribuía para essa situação. Conforme o documento, havia pouca interação entre os professores tutores e os efetivos, pois se tratava de profissionais que, em regra, até então não se conheciam, não conheciam a instituição onde passavam a trabalhar temporariamente e acabavam disputando espaço com os efetivos. ${ }^{10}$

\section{As Tecnologias Digitais de Informação E COMUnicaÇÃo (TDICs) E A FORMAÇÃo}

Muitos alunos do curso examinado na minha pesquisa eram totalmente leigos na lida com as tecnologias digitais de informação e comunicação, necessitando da ajuda de terceiros, geralmente dos filhos, para acessar e-mails, interagir nos fóruns, salvar e imprimir aulas, documentos, orientações. Uma solução foi organizar treinamentos nos polos explicando detalhadamente o 
uso do ambiente de ensino-aprendizagem, ou seja, familiarizando os alunos com a modalidade de ensino e o design didático próprio do AulaNet.

Posteriormente, todos os cursistas receberam um CD explicando passo a passo como lidar com a educação a distância, ou seja, um tutorial específico sobre o curso de licenciatura que eles estavam iniciando. Em decorrência dessas ações, tutores presenciais e a distância que colaboraram na pesquisa atestam que, aos poucos, os cursistas foram desenvolvendo habilidades para lidar com as TDICs. Muitos passaram a "ver esse instrumento novo como um desafio, que era necessário vencer essas dificuldades (Questionário, tutora presencial, polo de Teixeira de Freitas, Bahia, 16 set. 2012). A professora Andréa Queiroz avalia que, por volta do "terceiro período, [os alunos cursistas] já estavam inteirados e criaram uma rotina de estudos" (Questionário, tutora a distância, polo de Aracaju, Sergipe, 2 jul. 2013).

Outro professor disse que foi necessário fazer um deslocamento, no sentido de se desfazer das formas tradicionais de conceber a aprendizagem, para poder lecionar no ensino a distância: "O desafio era transformar a questão que se apresentava em uma boa oportunidade de ensino" (Entrevista, tutor a distância, polo de Bacabal, Maranhão, 4 out. 2012).

Desse modo, compreende-se que a experiência resultou em dois processos de aprendizagem: os professores leigos se tornaram formalmente professores de história, e também houve uma espécie de letramento em TDICs. Há convergência no argumento da tutora a distância e no do tutor presencial:

Eu acho que, nesse sentido, o curso evoluiu de uma maneira muito boa e, para eles, foi fundamental. Eles de fato se alfabetizaram nessa linguagem da informática, eles saíram alfabetizados nisso. Eu acho que eles aprenderam a lidar melhor com a informática. (Entrevista, tutora a distância, polo de Aracaju, Sergipe, 13 set. 2012)

Muitos professores-cursistas, grande maioria, não tinham contato algum com o uso do computador e internet. Somente tinham acesso a essas ferramentas nas próprias escolas e nas secretarias municipais de Educação. Apenas uns 30\% tinham computador em casa interligado à internet ... As principais dificuldades eram no momento de envio das tarefas, pois não memorizavam as formas de anexação dos arquivos. Atrelado a isso estava o problema do acesso à internet $\mathrm{e}$ da própria disponibilidade dela, pois, quando conseguiam, [a internet] nos seus 
municípios era lenta e isso causava desestímulos. (Questionário respondido por Francisco Gleison da Costa Monteiro, tutor presencial, polo de Tianguá, Ceará, 2 out. 2012)

É possível afirmar que a principal razão das evasões no curso foi a não adaptação ao ensino a distância. Um primeiro exame mostrou, como já foi dito, que aqueles que perseveraram foram os que conseguiram romper a barreira inicial de operar com as TDICs. Além disso, era necessário conscientizar-se de que, nessa modalidade de ensino, boa parte do sucesso do empreendimento depende, sobretudo, da capacidade de gerir o seu próprio tempo, já que não existe uma rotina rígida preestabelecida que determine a presença em um dado lugar por um número determinado de horas. Em outras palavras, o desempenho satisfatório do aprendizado exige, nessa modalidade de educação, uma autogestão do tempo realista e diária.

Uma professora cursista que já conhecia a modalidade de ensino a distância afirmou que, no geral, é necessário ter "disponibilidade e boa vontade para realizar todas as etapas solicitadas pelos professores virtuais". Segundo ela, "no começo foi um pouco difícil conciliar, pois era muita coisa ao mesmo tempo, muitas disciplinas, e a maior dificuldade foi a falta de um professor presencial para tirar as dúvidas" (Questionário por e-mail, cursista, polo de Teixeira de Freitas, Bahia, 28 mar. 2012).

A qualidade do serviço de internet oferecido nos polos foi um problema apontado pela coordenação central do curso, identificado pelos cursistas e também pelos tutores presenciais e a distância, assim como sinalizado no relatório de monitoramento do TCU. A questão da qualidade da internet era uma unanimidade em termos de dificuldade. Em geral, o serviço ou era discado ou era com sinal de rádio. Os alunos não conseguiam se comunicar ou, quando conseguiam, a conexão era muito lenta.

Constata-se que, apesar de as TDICs aproximarem os cidadãos do Estado, elas precisam ser mais desenvolvidas, faltam investimentos na estrutura material para essa modalidade de ensino, e os recursos humanos muitas vezes não alcançam o desenvolvimento técnico, ou então não fazem o investimento necessário para viabilizar esse tipo de ensino.

É fundamental que todos os profissionais envolvidos no planejamento da ação tenham em mente que acessar os conteúdos e oportunizar condições para 
que os cursistas enviem os trabalhos com rapidez é condição necessária para o adequado encaminhamento do projeto. Para minimizar o problema da internet, a coordenação criou outros mecanismos de aproximação, como uma linha telefônica gratuita.

$\mathrm{Na}$ formação presencial se aposta muito na relação professor-aluno para o efetivo êxito da aprendizagem, já que a interação ocorre preferencialmente na sala de aula. No ensino a distância, uma satisfatória relação professor-aluno também é imprescindível, mas são necessários diversos outros canais capazes de promover interação e comunicação. É preciso que os gestores tenham clareza da necessidade de proporcionar um vínculo efetivo entre o curso e o aluno para que ele acredite no projeto, apesar da distância física.

\section{SOBRE OS LIMITES DA FORMAÇÃO}

Analisei a dinâmica de aprendizagem dos professores cursistas no ambiente de aprendizagem virtual por meio do fórum de debates da disciplina História da África. Os cursistas deveriam interagir com o professor tutor a distância e com os seus colegas de classe a partir de uma questão problematizadora apresentada ao final de cada aula-texto. Essa metodologia foi comum a todas as outras disciplinas do curso de licenciatura em história examinado em minha pesquisa. A disciplina História da África apresentou seis questões problematizadoras. Os 765 cursistas postaram 5.866 mensagens no fórum de debates dessa disciplina.

Um dos componentes da avaliação era essa participação online. No final do semestre, o sistema gerava um relatório de cada aluno, informando quantas vezes ele havia entrado no fórum de debates da disciplina no qual estava inscrito. Ao lado dessa quantificação, cabia ao tutor avaliar a qualidade das participações no fórum de debates, considerando, além das respostas dos cursistas às questões problematizadoras, também a interação com os outros colegas de turma e com o seu próprio tutor. Ou seja, para ser bem avaliado, o cursista deveria participar constantemente do fórum de debates, postando as suas respostas, refazendo-as caso não alcançasse os objetivos da aula e comentando os registros dos colegas de turma para que, assim, houvesse uma dinamização com a circulação de ideias e de impressões sobre os textos, o que consequen- 
temente promoveria um ambiente de aprendizagem cooperativo e colaborativo (Moran, 2003).

Uma análise qualitativa do fórum mostrou algumas características desse grupo de cursistas na aprendizagem via formação a distância. Foi possível identificar recorrências nas estratégias de participação. Era comum interagir no fórum de debates postando breves resumos da aula-texto. Alguns postaram bons resumos, mas, ainda que fossem bons, isso não significava responder a tarefa do fórum. Outros cursistas recortavam da aula-texto algumas frases, montavam um pequeno texto e postavam como resposta. Outros usavam algumas frases do próprio texto da questão-problema do fórum de debates da aula para responder a tarefa, ou seja, tratavam de escrever diferentemente a mesma coisa, de transformar o que era uma pergunta em resposta. Alguns elaboravam respostas genéricas e, assim, acreditavam estar contribuindo com o fórum de debates.

Provocada a tecer considerações sobre a aprendizagem nessa experiência de formação, a tutora de um polo do estado do Ceará que trabalhou com diversas disciplinas ponderou que, no Ceará,

a participação ficou maior nos fóruns porque eles já me conheciam também e então já chegavam com mais intimidade no segundo semestre. Aí falavam mais, respondiam mais as perguntas, porque a gente começa a provocar quando as respostas são muito simples, né? “Tô respondendo para ganhar meu ponto de fórum", mas não chegou nem perto da reflexão que a gente queria, e a gente joga um pouquinho mais. Aí eles retornavam para tentar desenvolver mais, então tem um crescimento nesse sentido. (Entrevista, tutora a distância, polo de Aracati, 18 set. 2012)

A reflexão da tutora informa o jeito de aprender dos cursistas do seu polo e revela uma questão de suma importância, que é a atuação do tutor no processo de aprendizagem. Esse profissional precisa estabelecer uma sintonia, um vínculo com seus alunos, condição relevante no processo de aprendizagem e de perseverança de muitos nessa modalidade de ensino. Segundo Rumble (2003, p.72) "há alta correlação entre demora na correção de trabalhos e abandono dos cursos", por exemplo (Rumble, 2003). Essa constatação revela o papel crucial do tutor para o sucesso dessa modalidade de formação. 
Pude constatar também respostas idênticas postadas por cursistas de turmas diferentes, mas do mesmo Polo Municipal de Apoio Presencial. Essa prática também foi citada na entrevista de uma tutora a distância que trabalhou com turmas de Sergipe. Segundo ela, "nos polos, as pessoas se encontravam, tinha algum colega que não havia feito a tarefa, aí eles dividiam a tarefa. Isso aconteceu. Mas isso acontece também no presencial" (Entrevista, tutora a distância, polo de Aracaju, 13 set. 2012).

As situações de interação cotidianas identificadas nessa experiência de formação, todavia, são também comuns no ensino presencial, como pontuou a professora Andréa Queiroz:

De um modo geral, os que enfrentavam problemas na aprendizagem, seja na Bahia ou em outros estados (lecionei em todos), não diferiam muito das questões dos meus alunos do ensino presencial (também sou professora do curso de história de outra universidade particular). Eram trabalhadores que enfrentavam extenuantes jornadas para se dedicarem à empreitada de estudar novamente. (Questionário por e-mail, tutora a distância, polo de Aracaju, 2 jul. 2013)

Os cursistas se encontravam quinzenalmente nos polos e também podiam usar o espaço a qualquer hora para estudar, pesquisar e responder as tarefas no laboratório de informática. Para os cursistas que não tinham computador, o que deveria ser feito no decorrer dos dias acabava acumulado e era feito somente no Polo Municipal de Apoio Presencial. Aqueles que tinham uma carga horária de trabalho muito grande também não tinham tempo disponível de fazer as leituras e responder as tarefas. O momento para estudar os conteúdos acumulados acabava se dando apenas nesses encontros quinzenais, quando se tinha a oportunidade de ler, discutir com os colegas, receber orientação do tutor presencial etc. Esse momento, todavia, servia para que alguns cursistas trocassem tarefas, que depois seriam postadas nas suas respectivas turmas.

As tarefas direcionadas aos cursistas no final das aulas demandavam que eles relacionassem leituras e documentos, que comparassem experiências históricas, que chegassem às conclusões a partir de reflexões que também precisavam ser coletivas, ou seja, era necessário participar do fórum para elaborar e reelaborar o que se tornaria a sua resposta. Dessa maneira se promoveria a aprendizagem de todos. Em postagem direcionada a uma turma do polo de 
Imperatriz, Maranhão, a tutora a distância revela que muitas vezes os cursistas tiveram dificuldades para compreender os textos:

Concordo contigo: esta aula é muito difícil! São muitos detalhes apresentados num espaço curto. $\mathrm{E}$ a questão do fórum exige uma leitura muito cuidadosa da aula. A melhor estratégia é fichar a aula para poder "digeri-la" bem.

Não sei como você fez, mas o resultado está muito bom! Espero que seus colegas leiam a sua resposta e se sintam mais confiantes para trilhar seus caminhos. (Fórum de debates, tutora a distância, polo de Imperatriz, Maranhão, 7 out. 2010)

Foi possível constatar também que a internet se revelou um espaço de pesquisa recorrente para os cursistas, o que revela certo domínio das TDICs, pois saber manipular as ferramentas da internet para ter acesso ao conhecimento acadêmico se constituiu como condição fundamental ao sucesso da formação. Os professores-autores disponibilizaram, no final das aulas-texto, uma bibliografia complementar, e quase todos os textos podiam ser encontrados nos sites de instituições acadêmicas confiáveis. Contudo, os cursistas recorreram muito a blogs temáticos, páginas de busca e à página da enciclopédia online Wikipédia, que disponibiliza gratuitamente uma infinidade de dados elaborados por colaboradores anônimos. A prática de copiar trechos inteiros de um texto lido foi comum.

A internet de fato se revelou o modo mais fácil de ter acesso ao conhecimento para muitas pessoas, incluindo os professores. Contudo, professores e historiadores não podem tomar as leituras feitas nesses e em outros veículos de divulgação do conhecimento como verdades infalíveis. A prática de confrontar as informações é indispensável e faz parte do ofício.

Os livros didáticos também foram muito citados pelos cursistas no fórum de debates da disciplina. Os cursistas postaram trechos inteiros de livros didáticos sem qualquer questionamento ou análise. Era apenas mais uma informação a contribuir com o fórum. Novamente, essa prática revela que poucos cursistas tiveram o cuidado de elaborar uma tarefa autoral. A despeito dos diversos estudos críticos sobre os manuais didáticos, é possível verificar que eles ainda constituem um dos principais recursos de informação para professores.

Nas situações em que os cursistas postavam simples resumos das aulas ou respostas generalistas, constatei que alguns tutores chamavam a atenção dos 
alunos para que voltassem ao fórum e contribuíssem de modo coerente, respondendo com propriedade a questão problematizadora da aula estudada. Passado um tempo, os cursistas retornavam ao fórum de debates com novas contribuições, algumas reelaboradas, mas outras que se resumiam a trechos de textos lidos em outras fontes sobre o conteúdo da aula em destaque.

\section{CONSIDERAÇÕES FINAIS}

De início, o curso de licenciatura em história significou para muitas professoras um aumento da já exaustiva jornada de trabalho. Tratava-se de uma formação em serviço com uma bolsa auxílio no valor de 100 reais que não iria fazê-las deixar de trabalhar em algum turno. Essas mulheres tiveram então que abrir mão dos eventos de família e dos grupos de sociabilidade para realizar o projeto da licenciatura.

Nesse tipo de investimento longo, o apoio dos familiares é muito importante, porque significa a aprovação do projeto. Em muitas ocasiões foram os filhos dessas professoras, alguns deles também na universidade, que começaram a auxiliá-las no uso da internet, ensinando-as a usar o correio eletrônico, a fazer download das tarefas e textos, a postar mensagens etc. Por meio dessa experiência de curso de licenciatura em história temos uma ideia de como se encontra a realidade de trabalho e de desenvolvimento profissional dos professores no país.

Constatou-se que essa política de formação em serviço atingiu um conjunto de professores, ou melhor, professoras, com uma longa, porém precária trajetória de trabalho por conta de uma formação inexistente ou inadequada às atividades intelectuais e laborativas que desempenhavam, algumas havia décadas.

Políticas públicas de formação inicial (para a profissionalização) e continuada (para a atualização) de professores são imperativas. Iniciativas de desenvolvimento profissional geridas por várias instituições precisam estar conectadas no sentido de haver o mínimo de ruído na comunicação para que as fragilidades da estrutura concebida não afetem o beneficiário da política. Do mesmo modo, é preciso que o projeto em toda a sua vigência inspire confiança e represente substantiva mudança na vida dos sujeitos diretamente afetados pela política (ver Rumble, 2003, p.72). 
O relatório de monitoramento dos programas Pró-Licenciatura e UAB elaborado pelo TCU chegou à conclusão de que a baixa oferta de tutores presenciais, a inadequação do horário de atendimento do tutor ao cursista nos polos e as dificuldades na interação com os tutores a distância foram problemas comuns à maioria dos cursistas atendidos por essa modalidade de ensino entre os anos de 2006 e 2008, pelo menos. De acordo com esse mesmo relatório, na avaliação dos tutores a distância, foi mais complicado lidar com a falta de estrutura das IES, o atraso das bolsas e o treinamento insuficiente para o ensino na modalidade a distância. Já os tutores presenciais apontaram a dificuldade de acesso à internet, a estrutura nos polos e a falta de microcomputadores para trabalhar como os principais problemas (ver Brasil/TCU, 2009, p.67).

No caso do curso em destaque neste estudo, os problemas apresentados aqui ocorreram, mas não inviabilizaram a formação. O comprometimento dos profissionais, combinado à credibilidade das instituições proponentes, mais as expectativas futuras de ganho econômico e reconhecimento social vislumbradas pelos professores cursistas deram a tônica do empreendimento. Portanto, se essa experiência de desenvolvimento profissional voltada para uma maioria de mulheres com muitos anos de docência teve limitações em razão da falta de experiência das várias instâncias envolvidas com o ensino a distância e com o uso das TDICs, e também por questões pessoais dos beneficiários diretos da política, ainda assim ela significou um largo passo à frente para centenas de profissionais que alcançaram ganho econômico, melhores condições de trabalho, reconhecimento social e realização pessoal. Como declarou uma professora-cursista do polo de Salvador, "os docentes precisam estudar enquanto lecionam. Porque desta forma eles conhecem, refletem, aplicam e mudam suas concepções" (Questionário por e-mail, cursista, polo de Salvador, Bahia, 25 mar. 2012).

\section{REFERÊNCIAS}

BOURDIEU, Pierre. A ilusão biográfica In: AMADO, Janaína; FERREIRA, Marieta (Coord.) Usos \& abusos da história oral. Rio de Janeiro: Ed. FGV, 1996.

BRASIL. CNE/CEB. Escassez de professores no Ensino Médio: propostas estruturais e emergenciais. Relatório produzido pela Comissão Especial formada pelos conselheiros Antonio Ibañez Ruiz, Mozart Neves Ramos e Murílio Hingel. Conselho 
Nacional de Educação, MEC, 2007. Disponível em: http://portal.mec.gov.br/cne/ arquivos/pdf/escassez1.pdf; Acesso em: 23 fev. 2012.

BRASIL/TCU. Relatório de monitoramento de auditoria de natureza operacional em ações de formação de professores (Ministro Valmir Campelo), 2009. Disponível em: http://portal2.tcu.gov.br/portal/page/portal/TCU/comunidades/programas_ governo/areas_atuacao/educacao/formacao $\% 20 \mathrm{de} \% 20$ professores\% 20 monitoramento\%201\%20promoex.pdf; Acesso em: 12 mar. 2013.

CAMPOS, Gilda H.; ROQUE, Gianna O.; FIOROTI, Ciléia. Formação de professores a distância: estudo de caso do Programa Pró-Licenciatura em História. In: XXVIII CONGRESSO DA SOCIEDADE BRASILEIRA DE COMPUTAÇÃO, 28. WIE Workshop sobre Informática na Escola. Belém do Pará: SBC, 2008. (Mimeo.)

CERNY, Roseli Zen. Gestão Pedagógica na educação a distância: análise de uma experiência na perspectiva da gestora. Tese (Doutorado em Educação) - Pontifícia Universidade Católica de São Paulo. São Paulo, 2009.

COSTA, Celso José; DURAN, Maria Renata da Cruz. A Política Nacional de Formação de Professores entre 2005 e 2010: a nova Capes e o Sistema Universidade Aberta do Brasil. RBPG, Brasília, v.9, n.16, p.263-313, abr. 2012.

FERREIRA, Maria Claudia. A formação para as relações etnicorraciais e a profissionalização em história: saberes e práticas docentes no contexto da educação a distância. Tese (Doutorado) - Programa de Pós-Graduação em História, Política e Bens Culturais do Centro de Pesquisa e Documentação de História Contemporânea do Brasil da Fundação Getulio Vargas (CPDOC/FGV). Rio de Janeiro, 2013. Disponível em: http://bibliotecadigital.fgv.br/dspace/handle/10438/11294.

GIOLO, Jaime. A educação a distância e a formação de professores. Educação e Sociedade, Campinas, SP, v.29, n.105, p.1211-1234, set.-dez. 2008.

MIRANDA, Cláudia. Colaboração intercultural e divisão de poder: perspectivas de descolonização entre professoras e estudantes de escola pública. In: ANDRADE, Marcelo (Org.) A diferença que desafia a escola: a prática pedagógica e a perspectiva intercultural. Rio de Janeiro: Quartet, 2009.

MONTEIRO, Ana Maria. Professores de História: entre saberes e práticas. Rio de Janeiro: Mauad X, 2007.

MOON, Bob. O papel das novas tecnologias da comunicação e da educação a distância para responder à crise global na oferta e formação de professores: uma análise da experiência de pesquisa e desenvolvimento. Educação e Sociedade, Campinas, SP, v.29, n.104 - Especial, p.791-814, out. 2008. Disponível em: http://www.cedes. unicamp.br; Acesso em: 22 jun. 2014.

MORAN, José Manuel. Contribuições para uma pedagogia da educação online. In: . Educação online: teorias, práticas, legislação, formação corporativa. São 
Paulo: Loyola, 2003. p.39-50. Disponível em: http://www.eca.usp.br/prof/moran/ site/textos/educacao_online/contrib.pdf; Acesso em: 22 jun. 2014.

MORÁN, José Manuel. O ensino a distância no Brasil. Educação \& Linguagem, v.12, n.19, p.17-35, jan.-jun. 2009.

OLIVEIRA, Romualdo Portela. Da universalização do ensino fundamental ao desafio da qualidade: uma análise histórica. Educação e Sociedade, Campinas, SP, v.28, n.100 - especial, p.661-690, out. 2007. Disponível em: http://www.cedes.unicamp. br; Acesso em: 22 jun. 2014.

PAIM, Elison Antônio. Do formar ao fazer-se professor. In: MONTEIRO, A. M.; GASPARELlO, A. M.; MAGALHÃES, M. de S. (Org.) Ensino de História: sujeitos, saberes e práticas. Rio de Janeiro: Mauad X; Faperj, 2007.

RABELO, J. J.; MENDES SEGUNDO, Maria das Dores; JIMENEZ, M. S. V. Educação para todos e reprodução do capital. Trabalho Necessário, ano 7, p.1-24, 2009. Disponível em: http://www.uff.br/trabalhonecessario/images/TN09\%20JIMENEZ,\%20S.\%20et\%20al.pdf; Acesso em: 16 jul. 2013.

ROQUE, Gianna O.; CASTRO, Simone B. Design didático na formação continuada em serviço de professores. In: CONGRESSO NACIONAL DE ENSINO SUPERIOR A DISTANCIA (EsuD), 6. Teresina, 2009. [Anais online]. Disponível em: http://hotsites.cursosccead.net/pesquisa/wp-content/uploads/2010/07/Artigo03. pdf; Acesso em: 12 mar. 2012.

RUMBLE, Greville. A gestão dos sistemas de ensino a distância. Trad. Marília Fonseca. Brasília: Ed. UnB; Unesco, 2003.

SALVUCCI, Mara; LISBOA, Marcos; MENDES, Nelson. Educação a Distância no Brasil: fundamentos legais e implementação. Revista Brasileira de Aprendizagem Aberta e a Distância, São Paulo: Abed, v.11, 2012. Disponível em: http://www. abed.org.br/revistacientifica/Revista_PDF_Doc/2012/artigo_04_v112012.pdf; Acesso em: 14 mar. 2013.

TARDIF, Maurice. Saberes docentes e formação profissional. 10.ed. Petrópolis, RJ: Vozes, 2010.

UNESCO/DAKAR. Educação para todos: o compromisso de Dakar. 2.ed. Brasília: Unesco; Consed. Ação Educativa, 2001. Disponível em: http://unesdoc.unesco. org/images/0012/001275/127509porb.pdf; Acesso em: 16 jul. 2012.

\section{NOTAS}

${ }^{1}$ Sobre a expansão das matrículas no ensino fundamental, ver OLIVEIRA, 2007.

${ }^{2}$ Uma análise sobre o papel crucial que os documentos citados atribuem ao trabalho do 
professor no alcance da qualidade educacional pode ser vista em RABELO; MENDES SEGUNDO; JIMENEZ, 2009.

${ }^{3}$ Uma análise sobre a legislação que regula a EAD pode ser encontrada em SALVUCCI; LISBOA; MENDES, 2012. Sobre as modalidades de formação a distância ofertadas ao ensino superior ver MORÁN, 2009.

${ }^{4}$ Uma reflexão sobre o aumento dos cursos superiores, voltados quase todos à formação de professores e controlados majoritariamente pela iniciativa privada está em GIOLO, 2008.

${ }^{5}$ Atualmente, a formação inicial e continuada dos docentes está sob a responsabilidade da Diretoria da Educação Básica (DEB), que é subordinada à Coordenação de Aperfeiçoamento de Pessoal de Nível Superior (Capes). A Capes também responde por outras políticas de formação de docentes em exercício da profissão, como o Plano Nacional de Formação de Professores da Educação Básica (Parfor) e o sistema Universidade Aberta do Brasil (UAB). Ver COSTA; DURAN, 2012.

${ }^{6}$ A Rede Nacional de Formação Continuada de Professores (Rede) foi criada em 2004 e é destinada aos professores da educação básica das escolas públicas. O Pró-Letramento foi criado em 2005, com a função de apoiar a ação pedagógica (áreas de linguagem e matemática) dos professores que atuam nos anos iniciais do ensino fundamental, funcionando em parceria com a Rede, os estados e os municípios.

${ }^{7}$ A Undime é uma entidade nacional sem fins lucrativos que congrega os dirigentes municipais de educação. Ela existe desde 1986, com sede em Brasília. A instituição indica membro para o Conselho Nacional de Educação e participa dos processos de discussão, formulação e implementação de políticas nacionais de educação. Fonte: http://undime.org.br/ institucional/o-que-e-a-undime/; Acesso em: 9 mar. 2012.

${ }^{8}$ Cf. Capítulo 1 de minha tese, FERREIRA, 2013.

${ }^{9}$ Nem todos meus interlocutores autorizaram a divulgação de seus nomes em minha pesquisa, razão pela qual algumas vezes aparecem aqui com nomes, e outras, não.

${ }^{10}$ Ver BRASIL/TCU, 2009, p.59. Uma reflexão sobre gestão da formação de professores em EAD está em CERNY, 2009.

Artigo recebido em 30 de maio de 2014. Aprovado em 27 de junho de 2014. 